\title{
An investigation on implementation of clinical governance: A case study of an Iranian hospital
}

\author{
Elahe Parsaamal* and Yashar Salamzadeh
}

Department of Management, Payame Noor University, Tehran, Iran

CHRONICLE ABSTRACT

Article history:

Received June 22, 2013

Received in revised format

28 August 2013

Accepted 15 September 2013

Available online

September 172013

Keywords:

Clinical Governance

Health care industry

Dr Shariati hospital

Risk management

\section{Introduction}

According to Chandra (2009), the Clinical Governance (CG) was introduced in 1998 at the NHS in England as an umbrella for both covering all the clinical activities and promoting continuous quality of clinical care. The CG concept was evolved in the late $20^{\text {th }}$ century and the early $21^{\text {st }}$ century and was employed for higher quality and safer services (Luu Trong, 2012). Some studies state that the CG is a system where the NHS organization is accountable for continuous quality improvement on the basis of higher standards in creating an appropriate environment for clinical cares (Luu Trong, 2012). The CG is a framework in which the organizations present the clinical services are also responsible for continuous quality improvement and they support the high standards of services by creating an environment for flourishing the clinical service excellences (Gabriel \& Liam, 1998). In fact, CG is a

*Corresponding author.

E-mail address: elahe.parsa68@gmail.com (E. Parsaamal)

(C) 2013 Growing Science Ltd. All rights reserved.

doi: $10.5267 /$ j.ms 1.2013 .09 .020

Clinical Governance (CG) generally aims to enhance the quality of clinical services, increases the accountability of those who are responsible for health affairs. This study examines the quality of presenting medical services in Dr. Shariati hospital in Tehran after executing the CG project. To attain the aforesaid goal, this research also surveys the implementation rate of CG in Dr. Shariati hospital based on the CG seven-pillar model. The study is a descriptive and crosssectional research fulfilled in summer 2013. Statistical population contains the employees of Dr. Shariati hospital in Tehran and the research sample includes 80 people of the mentioned population who were selected, randomly. Data was gathered through a questionnaire and the experts confirmed its validity and the reliability was approved via Cronbach's alpha of 0.947 and then, the analysis was carried out by the SPSS software and T-test. The findings for each CG pillar in Dr. Shariati hospital have placed less than the medium amount and they are not in desirable level. The CG at the above-mentioned hospital places in a medium rank so that the efforts by the managers will create successful changes at the hospital; meanwhile, the managers will be able to utilize the CG method in systematic prediction of changeable priorities to present the best strategies for achievable performance of managerial techniques and processes.

(c) 2013 Growing Science Ltd. All rights reserved. 
unit and comprehensive system, which represents continuous quality improvement for services and provides sufficient supports in a systematic model (Luu Trong, 2012). In addition, CG is considered as a concept, which creates a suitable environment within organizations to present health services by being accountable via continuous quality improvement and patient safety (David, 2011). Together with the health quality improvement, CG provides the possibility of documentation increasingly in order to prevent any mistake in cure process; meanwhile, it creates maximum satisfaction for patients due to the special rights considered for them (Wright \& Hill, 2003).

\section{Research Background}

As a representative of Greek hospitals, Eleonora et al. (2011) studied the status of two public hospitals and one semi-public hospitals in 2010 to make an assessment on the readiness of the hospitals for accepting the $\mathrm{CG}$ in their own atmosphere. They reported that the organizational atmosphere would act as an instrument for understanding, improvement, and readiness of organizational culture for accepting organizational culture. Eleonora et al. (2011) utilized the Australian four-pillar model introduced originally by world health organization (WHO) in 1983. The four pillars of the aforesaid model are as follows:

1. Professional performance,

2. Resource allocation,

3. Risk management,

4. Patient satisfaction.

Anne et al. (2006) performed a survey on CG as an opportunity for quality improvement and increase in patient safety. Som (2009) introduced two ways in his 2009 study that represented an increase in cures and cares of patients as well as a decrease in their waiting time in one hand, and an enhancement in the cure quality of the patients on the other. Chandra (2009) examined the people's perceptions on CG by interviewing 33 people who were handling important responsibilities such as general managers, doctors, nurses, supervisors, etc. and found out that CG for people in various levels were different and this kind of perceptions would act as an obstacle for continuous quality improvement. Feredrick et al. (2008) examined the effect of CG on culture and quality improvement

and reported that $\mathrm{CG}$ would cause an improvement both in health system and quality promotion. John et al. (2008) reported that the electronic information system could make CG more effective in the field of improving the patients' status.

\subsection{Clinical Governance Models}

There are different CG models in the literature and one of these models is the western Australian four pillar models, which presented by the west Australia public health system in 2001 for development and performance of hospitals and health services. The overall shape of the model consists of four pillars where each one represents an aspect of the patients' rights.

1. Efficiency

2. Risk Management

3. Patient Satisfaction

4. Professional Effectiveness) (Fong, 2005)

Another model is the one used by the national medical system of England. This model is a seven-core or seven-pillar introduced by the Iranian ministry of health due to its comprehensiveness, which includes Patient and public involvement, Risk management, Education and training, Use of information, Clinical effectiveness, Clinical audit and Staff management (Gabriel \& Liam, 1998). In 
health care system, patients must be treated by respect and honesty in any place they are planning to have trip; meanwhile, they deserve to be shared in decisions for their cure trends (Currie et al., 2005). A relation has been established between the Clinical Governance and PPI (Patient and Public Involvement) by the NHS organization since 1999 and when the UK government defined the role of Clinical Governance in systematic approach for quality improvement (Savory, 2010). The patients deserve the right to be involved directly or indirectly in medical services plans, development and requirements for changing the service methods, and decisions, which have influences on the services (Savory, 2010). The patients must be involved in designs, presentation, and the assured quality of the services. Actual power of the patient and public together with the information and choices will have vital effects on promoting the NHS. It does not give the patients this message that they must accept each service they receive, but in return, it presents them as a dynamic and accountable service (ColinThome, 2013). Since considering each policy and decision making associated with the health services will have influences on the lives of patients, the patient. The public involvement in health affairs together with presenting the health top policies in the developed countries may be considered as a citizenship right. Meanwhile, it will also have a moral and conscientious perspective and it can be assumed as justice and accountability as well as improvement in health consequences, life quality and patients' satisfaction. Some people explain Patient and Public Involvement in terms of individual and collective levels. According to this opinion, individual involvement implies the person's involvement in making medical decisions associated with his/her own health sides, and collective involvement addresses an active involvement by a group of people or a person as a representative of a group in determining procedures, policies, and planning of health system (Haxby, 2010).

\subsection{Risk Management}

The patients have the right to be expected that their cares must be compatible with the best conditions and standards and it also must be based on the latest scientific and clinical proofs (Currie et al., 2005). The probability of emerging danger means creating an unpleasant event or loss; meanwhile, it can be part of our natural life. We are always exposed to a wide range of risky cases and we spend most part of our time in preventing accidents, injuries, or unpleasant events. Predicting events and risks together with the decrease in possibility of emerging them is the same as risk management (John et al., 2008). Evaluating the events is not only useful for finding culprits and make punishment and castigation, but also it provides the possibility of learning, diagnosis, and cure of a major problem in design and performance of health system (Byers \& white, 2004).

\subsection{Education and Training}

Continuous Professional Development (CPD) is necessary for an organization for CG implementation. CPD is continuous learning process for all professional people and teams who are able to expand their capabilities for encountering the patients' requirements and give them health services. The fundamental of CPD means that it is not only for clinical staff like doctors (Chambers \& Walkley, 2000). One of the tools for CPD is the Personnel Development Plan (PDP). PDP is a continuous process for evaluating the training needs and having plan for attaining the related requirements. This process is being supported by a system, which evaluates the learning process regularly; meanwhile, it plans both the future programs and progress rates. Documenting the aforesaid process is in fact the presentation of the PDP, which helps the staff to both prioritize their goals and determine their own progress rates (Clark \& Smith, 2002).

The infrastructure information of each system possesses standard and quality (Currie et al., 2005). Knowledge, skill, and tools provide information for gathering, management, using, and sharing in order to support the health service improvement (John, Catherine, \& Moira, 2008). The quality was considered as the reforms' core after introducing CG to the English health system for implementation in 1998. Integrating all effective activities on patients' cares in a unit strategy including promotion of 
information quality, cooperation improvement, work group, and equalizing the health and medical service methods are the primary objectives of CG. It is clear that every organization requires appropriate information for presenting any improvement in its quality. Good information is essential for planning, execution, management, and service evaluation (Currie et al., 2005). High quality information, information management, and information technology are essential for improvement in patient's care and the effectiveness of CG implementation. Accurate usage of information is a way for ensuring that the presented services are effective, impressed, and economical (John et al., 2008). Shortage of input data is blamed for failure of information technology in healthcare services. Furthermore, if the data lacks sufficient accuracy and no effort is performed for information improvement; usage and application of the information will encounter with problem. Meanwhile, the major deficiency may happen in the system so that the clinical staff would not tend to gather the related data.

\subsection{Clinical Effectiveness}

Clinical effectiveness is the result of applying the best knowledge, which is originated from an updated research and experience to perform accurate clinical processes and attain the desired clinical consequences for patients (Willcocks, 2003). In addition, CG indicates the utility of the results of implementing a medicine or a medical diagnostic method in producing the best clinical consequences for patients. Measuring the effectiveness of the services is the first fundamental step in the healthcare quality improvement. Two parameters of price and effectiveness are the two areas in health system, which form the future of health services, while the development in improvement and service systems together with a scientific approach in planning, analyzing, and evaluating are required as well. All the health systems have developed some policies for improving the healthcare services in recent years (Pantouvakis \& Mpogiatizidis, 2013). Evidence Based Medicine (EBM) is a merger of the best evidences from clinical researches, clinical experiences, and the patients' conditions and preferences. The reason for learning EBM is that the medical information has many capacities and they are still developing (Samanta \& Samanta, 2005).

\subsection{Clinical Audit}

The simple and ordinary but understandable definition of clinical audit, which was introduced in 1989 for the first time, can be stated as follows: "Audit is a process which promotes the quality of healthcare through supervising the medical affairs and applying the required changes" (Garg et al., 2012). Clinical audit is a process for promoting the quality of clinical services, which reviews systematically the healthcare trends by considering the clear and explicit standards. Meanwhile, it identifies and applies the required changes for improving the structure, process, and healthcare consequences. It also reviews and controls the processes again to assure that the changes associated with the improvement of service quality in the field of health system have been applied accurately.

Clinical audit normally analyzes various aspects of current medicines including diagnosis, treatment, healthcare, and optimal usage of resources and then compares them with the standards to detect the differences and failures and tries to present services in accordance with the best medical approaches. These standards, which define measurable aspects of the healthcare, must be always based on evidences (Komuravelli \& Smith, 2011).

The patients have rights to be cared by the professional staff and updated skills and expertise (Currie, et al., 2005). When CG became important, the subject of human resources was taken into consideration simultaneously (Som, 2007). Portraying the Magnet hospitals' performances in the United States of America in 2002 disclosed that there was a significant relationship between the performance improvement of human resources and healthcare improvement. Thus, the human resources management was declared as the key concept for performance improvement in the UK (Hyde et al., 2013). Service promotion to patients may be executed through complying with the best 
practices in human resources management by continuous improvement of staff job satisfaction and development of their individual and occupational skills (Som, 2007). This shows the importance of staff management in performing the governance of clinical services.

The objective of this study is to analyze the implementation rate of Clinical Governance in Dr. Shariati hospital by surveying seven major areas and attempting to continue toward the Clinical Governance in order to be ensured that the healthcare measures are being presented to public by using the highest healthcare standards. In doing so, we would be able to increase public confidence toward the hospital services and also attain the health organizational responsibility by preventing errors as well as the optimal usage of resources.

\subsection{The proposed study}

In 1965, the first part of the central building of the nuclear medicine and a research center for Internal Lymph Nodes affiliated to the University of Tehran was inaugurated and later it became a hospital known as Dr Shariati hospital. This study aims to analyze the implementation rate of CG at Dr. Shariati hospital in Tehran in 2013 using questionnaire and it may be considered as a descriptivesurvey research. For analyzing the data, descriptive statistics (frequency distribution, mean, variance, standard deviation) and inferential statistics (One Sample T-Test) have been utilized by SPSS software. The statistical population of the research includes doctors, managers, heads of various sections, and supervisors of the hospital in 2013. Random sampling has been used for the research sample. The sample size was selected 80 people using Morgan Table. The questionnaire distributed among 120 people but only 51 people completed them. The questionnaire incorporates two parts: The first part contains demographical information and the second part includes 67 questions, which examines the managers and staff perceptions on the implementation rate of the Clinical Governance. The latter part has been divided into seven identical sections so that 7 to 13 questions have been asked from the considered population. In addition, responses to each section represent the implementation rate of one pillar of Clinical Governance so that the implementation rate of each pillar from 7 pre-defined pillars can be measured by analyzing the responses.

The first eight questions examine the implementation rate of risk management at the hospital including the awareness and training of personnel on the risk management, the records of occurred errors, being acquaintance to Failure Model and Effect Analysis (FMEA), the method of error analysis via Root Cause Analysis (RCA), and using the results of analyzed errors.

The second nine questions are related to the method of using information. In this part, some questions have been asked about the items such as Hospital Information System (HIS), being aware of working procedures, and usage and efficiency rate. Then, some other questions on suggestion and complaint system as well as focusing on information originated form measuring consumers' satisfaction have been discussed.

For the section entitled "Patient and Public Involvement", 13 questions have been asked in which the hospital plan for making patients aware of their rights and their observation rate by the staff have been measured. Furthermore, some items such as the hospital notice on the confidentiality of the patients' information, selecting a suitable doctor, choosing the type of treatment by patient, and care plans after leaving hospital will be evaluated. Finally, the focus rate of hospital on patients' satisfaction will be taken into consideration.

In this section, we ask some questions like the rate of staff training, establishment rate of staff satisfaction at hospital, method for justifying newcomers, reward system for staff, and a set of measures by hospital for keeping skilled employees together with making them alliance with the shared goals have been discussed. 
The next nine questions are related to the pillar entitled "Education and Training" in which the usage rate of Personal Development Planning (PDP)'s forms, staff training, and appropriate knowledge sharing rate, and staff access to the educational booklets have been taken into consideration.

Questions associated with the effectiveness section focus on the staff acquaintance rate to Evidence Based Management (EBM), access rate and usage of Evidence Based Medicine, and the guidelines as well as their customization; meanwhile, control rate and complaints' feedbacks are also taken into account. Finally, in the section titled "Clinical Audit", the effectiveness rate, operation rate of audits done, checklists, and the impact of clinical audit on quality improvement are measured as well. To determine the reliability, Cronbach's alpha has been used and for specifying the validity, content validity method has been utilized. According to the results from reliability analysis tool, the coefficients for Cronbach's alpha are as follows; meanwhile the overall alpha was reported 0.947, which reveals the reliability of the used tools:

\section{Table 1}

Cronbach's alpha

\begin{tabular}{lll}
\hline & Clinical governance pillars & Cronbach's alpha \\
\hline 1 & Patient and public involvement & 0.728 \\
2 & Risk management & 0.838 \\
3 & Education and training & 0.885 \\
4 & Use of information & 0.822 \\
5 & Clinical effectiveness & 0.821 \\
6 & Clinical audit & 0.794 \\
7 & Staff management & 0.881 \\
\hline
\end{tabular}

In this study and based on 5-point Likert Scale, the maximum and minimum scores for each dimension of Clinical Governance are 5 and 1, respectively. If the score for a component is at least 60 percent of the total score, the component can be considered acceptable. Thus, the amount of 3 is a benchmark and each score greater than 3 reveals the utility of the status. For analyzing the data, descriptive statistics (frequency distribution, mean, variance, standard deviation) and inferential statistics (One Sample T-Test) have been utilized by SPSS software.

\section{Results}

Table 2 shows the average scores of the components for Clinical Governance and Tables 3-9 show the average scores of each component of the Clinical Governance in the studied sample.

Table 2

Clinical governance pillars T-Test

\begin{tabular}{lcccccc}
\hline & Mean & $\begin{array}{c}\text { Average } \\
\text { percent }\end{array}$ & Std deviation & p-value & df & $\mathrm{t}$ \\
\hline Patient and public involvement & 2.5639 & 51.278 & .50027 & .000 & 50 & -6.225 \\
Risk management & 2.7929 & 55.858 & .59120 & .016 & 50 & -2.501 \\
Education and training & 2.5427 & 50.854 & .56968 & .000 & 50 & -5.732 \\
Use of information & 2.8110 & 56.22 & .56003 & .020 & 50 & -2.410 \\
Clinical effectiveness & 2.9369 & 58.738 & .60249 & .458 & 50 & -.748 \\
Clinical audit & 2.6931 & 53.862 & .52191 & .000 & 50 & -4.199 \\
Staff management & 2.9631 & 59.262 & .67921 & .664 & 50 & -.388 \\
\hline
\end{tabular}

According to the results of Table 2, all seven clinical governance pillars in Shariati hospital maintain low values, which are less than the average and they could not gain expected score compared with others. Clinical audit with the mean of 2.9631 has gained the highest amount followed by education 
and training (2.8110), staff management (2.7929), clinical efficiency (2.6931), risk management (2.5639) and public and patients involvement (2.5427). The amount of p-value in education and training and clinical audit are more than 0.05 , which indicate that there are not significant differences between their mean and t-value

\subsection{Public and patient involvement}

Table 3 states that out of 13 items of public and patient involvement, 12 items are less than desired level in this hospital and complaint system establishment is in the best situation. $\mathrm{T}$ value is not significant and there is no significant difference between them. Corrective actions based on received complains (2.92) and Confiding patient's personal information (2.76) have the closest amount to three.

Table 3

Public and patient involvement- T-Test results

\begin{tabular}{|c|c|c|c|c|c|c|}
\hline \multirow[t]{2}{*}{ Items } & \multicolumn{6}{|c|}{$\mathrm{t}$ - value $=3$} \\
\hline & Mean & $\begin{array}{c}\text { Average } \\
\text { percent }\end{array}$ & $\begin{array}{c}\text { Std } \\
\text { deviation }\end{array}$ & p-value & df & $\mathrm{t}$ \\
\hline Complaint system establishment & 3.08 & 61.6 & 1.017 & .584 & 50 & .551 \\
\hline Corrective actions based on received complains & 2.92 & 58.4 & 771 & 471 & 50 & -.727 \\
\hline $\begin{array}{l}\text { Programing to inform patients and their families about the } \\
\text { patient's rights }\end{array}$ & 2.59 & 51.8 & 1.023 & .006 & 50 & -2.874 \\
\hline Training personnel for regarding the patient's rights & 2.43 & 48.6 & 1.005 & .000 & 50 & -4.040 \\
\hline $\begin{array}{l}\text { Orienting patients and their families about the patient's } \\
\text { rights charter }\end{array}$ & 2.45 & 49 & .757 & .000 & 50 & -5.182 \\
\hline Confiding patient's personal information & 2.76 & 55.2 & 1.050 & 116 & 50 & -1.600 \\
\hline $\begin{array}{l}\text { informing patients and their families about medical and non- } \\
\text { medical services }\end{array}$ & 2.41 & 48.2 & .829 & .000 & 50 & -5.068 \\
\hline $\begin{array}{l}\text { informing patients and their families about the way and the } \\
\text { process of treatment }\end{array}$ & 2.43 & 48.6 & .900 & .000 & 50 & -4.511 \\
\hline The right of choosing doctors and treatment team & 1.82 & 36.4 & .865 & .000 & 50 & -9.713 \\
\hline Informing patients and their family about his/her disease & 2.67 & 53.4 & .739 & .002 & 50 & -3.220 \\
\hline Programming for treatment after hospital discharge & 2.20 & 44 & .872 & .000 & 50 & -6.582 \\
\hline $\begin{array}{l}\text { Performing the program of satisfaction survey from patients } \\
\text { about treatment process }\end{array}$ & 2.67 & 53.4 & .841 & .007 & 50 & -2.832 \\
\hline Analyzing patients satisfaction survey questionnaire & 2.63 & 52.6 & .894 & .004 & 50 & -2.977 \\
\hline
\end{tabular}

\subsection{Risk management}

Table 4 shows that in Shariati hospital, out of eight items of risk management, seven items maintain a value less than desired level ( $\mathrm{p}$-value $<0.05)$. Therefore, there was a significant differences between mean and eligible value ( $\mathrm{t}$-value $=3$ ). All these amounts are significantly less than mean and just the value of FMEA strategies effectiveness exceeds the average but because p-value is more than 0.05 , we can claim that there is any significant difference.

\section{Table 4}

Risk management- T-Test results

\begin{tabular}{|c|c|c|c|c|c|c|}
\hline \multirow[t]{2}{*}{ Items } & \multicolumn{6}{|c|}{$\mathrm{t}-$ value $=3$} \\
\hline & Mean & Average(\%) & Std deviation & p-value & df & $\mathrm{t}$ \\
\hline $\begin{array}{l}\text { Informing personals about training course program about } \\
\text { risk management and necessary standards for patients safety }\end{array}$ & 2.61 & 52.2 & 0.850 & 0.002 & 50 & -3.293 \\
\hline Registering errors & 2.31 & 46.2 & 0.812 & 0.000 & 50 & -6.034 \\
\hline Orienting personals about FMEA strategies & 2.08 & 41.6 & 1.017 & 0.000 & 50 & -6.473 \\
\hline FMEA strategies effectiveness & 3.22 & 64.4 & 0.954 & 0.109 & 50 & 1.630 \\
\hline Performing FMEA strategies & 2.49 & 49.8 & 0.903 & 0.000 & 50 & -4.033 \\
\hline $\begin{array}{l}\text { Personal awareness about analyzing medical errors by RCA } \\
\text { in SENTINAL situations }\end{array}$ & 2.27 & 45.4 & 0.896 & 0.000 & 50 & -5.781 \\
\hline Analyzing medical errors by RCA in SENTINAL situations & 2.31 & 46.2 & 0.810 & 0.000 & 50 & -5.036 \\
\hline $\begin{array}{l}\text { Using data gained in analyzing errors in learning and } \\
\text { preventing errors again }\end{array}$ & 2.61 & 52.2 & 0.827 & 0.001 & 50 & -3.388 \\
\hline
\end{tabular}




\subsection{Education and training}

According to Table 5, three out of nine items maintain desirable values. In other words, Pre-test posttest effectiveness in personal education and learning maintains the highest value. In addition, the value of $\mathrm{p}$-value for three items including Pre-test post-test effectiveness in personal, Personal awareness about the way of completing PDP forms, Possibility of sharing data, knowledge and experience are less than 0.05 .

Table 5

Education and training- T-Test results

\begin{tabular}{|c|c|c|c|c|c|c|}
\hline \multirow[t]{2}{*}{ Items } & \multicolumn{6}{|c|}{$\mathrm{t}$ - value $=3$} \\
\hline & Mean & $\begin{array}{l}\text { Average } \\
\text { percent }\end{array}$ & $\begin{array}{c}\text { Std } \\
\text { deviation }\end{array}$ & p-value & df & $\mathrm{t}$ \\
\hline Establishing personals training system based on PDP & 2.76 & 55.2 & .885 & .063 & 50 & -1.898 \\
\hline Performing continuing training personal policy & 3.18 & 63.6 & .740 & .095 & 50 & 1.702 \\
\hline Effectiveness in 10 necessary training course & 2.94 & 58.8 & 1.103 & .705 & 50 & -.381 \\
\hline $\begin{array}{l}\text { Pre-test post-test effectiveness in personal education and } \\
\text { learning }\end{array}$ & 3.41 & 68.2 & .983 & .004 & 50 & 2.990 \\
\hline Educating effects in personals growth and development & 3.18 & 63.6 & 1.072 & .245 & 50 & 1.176 \\
\hline Education and duty adaptation & 2.96 & 59.2 & .894 & .755 & 50 & -.313 \\
\hline Personal awareness about the way of completing PDP forms & 2.55 & 51 & .879 & .001 & 50 & -3.664 \\
\hline Staff's access to general and specialized books & 2.80 & 56 & .960 & .151 & 50 & -1.459 \\
\hline Possibility of sharing data ,knowledge and experience & 2.65 & 53 & .976 & .013 & 50 & -2.582 \\
\hline
\end{tabular}

\subsection{Use of information}

Table 6 demonstrates the results of our survey for use of information where six out of nine options maintain undesirable values, i.e. Mean $<3$. In our survey, Amount of using proposal system's information maintains the highest value (3.59) followed by Personal's awareness about the way of working with Hospital Information System (HIS) (3.55) and Effective HIS performance (3.14).

Table 6

Use of information- T-Test results

\begin{tabular}{|c|c|c|c|c|c|c|}
\hline \multirow[t]{2}{*}{ Items } & \multicolumn{6}{|c|}{$\mathrm{t}-$ value $=3$} \\
\hline & Mean & $\begin{array}{l}\text { Average } \\
\text { percent }\end{array}$ & $\begin{array}{l}\text { Std } \\
\text { deviation }\end{array}$ & p-value & df & $\mathrm{t}$ \\
\hline $\begin{array}{l}\text { Personal's awareness about the way of working with } \\
\text { Hospital Information System (HIS) }\end{array}$ & 3.55 & 71 & 0.783 & .000 & 50 & 5.010 \\
\hline Amount of using proposal system's information & 3.59 & 71.8 & 898. & .000 & 50 & 4.676 \\
\hline Effective HIS performance & 3.14 & 62.8 & 0.939 & .301 & 50 & 1.044 \\
\hline Amount of using complain system’s information & 2.35 & 47 & 0.913 & .000 & 50 & -5.063 \\
\hline $\begin{array}{l}\text { Amount of using personal satisfaction survey } \\
\text { information }\end{array}$ & 2.55 & 51 & 1.034 & .003 & 50 & -3.139 \\
\hline $\begin{array}{l}\text { Amount of using patient satisfaction survey } \\
\text { information }\end{array}$ & 2.37 & 47.4 & 0.802 & .000 & 50 & -5.608 \\
\hline Amount of using errors information & 2.69 & 53.8 & 0.844 & .010 & 50 & -2.679 \\
\hline $\begin{array}{l}\text { Giving each part of hospital feedback on the result of } \\
\text { analyzing information }\end{array}$ & 2.53 & 50.6 & 0.789 & .000 & 50 & -4.288 \\
\hline
\end{tabular}

\subsection{Clinical effectiveness}

Among 11 items of clinical effectiveness in this hospital, two items maintain desirable values and nine of them do not. In other words, Guidelines effectiveness maintains the highest and EBM orientation maintains the minimum amount. 
Table 7

Clinical effectiveness- T-Test results

\begin{tabular}{|c|c|c|c|c|c|c|}
\hline \multirow[t]{2}{*}{ Items } & \multicolumn{6}{|c|}{$\mathrm{t}-$ value $=3$} \\
\hline & Mean & $\begin{array}{l}\text { Average } \\
\text { percent }\end{array}$ & $\begin{array}{l}\text { Std } \\
\text { deviation }\end{array}$ & p-value & df & $\mathrm{t}$ \\
\hline EBM orientation & 2.08 & 41.6 & .845 & .000 & 50 & -7.790 \\
\hline EBM effectiveness & 2.57 & 51.4 & 1.153 & .010 & 50 & -2.671 \\
\hline $\begin{array}{l}\text { Clinical experts, faculties, nurses orientation } \\
\text { toward EBM and using clinical medicine } \\
\text { guidance }\end{array}$ & 2.57 & 51.4 & .964 & .002 & 50 & -3.194 \\
\hline $\begin{array}{l}\text { Possibility of online access information bank of } \\
\text { valid evidence medicine }\end{array}$ & 2.63 & 52.6 & 1.076 & .017 & 50 & -2.472 \\
\hline $\begin{array}{l}\text { Amount of access dose and the way of using } \\
\text { medicine in each relevant part of hospital }\end{array}$ & 2.98 & 59.6 & .883 & .875 & 50 & -.159 \\
\hline Guidelines effectiveness & 3.47 & 69.4 & 1.102 & .004 & 50 & 3.050 \\
\hline $\begin{array}{l}\text { Allocating budget for customizing and applying } \\
\text { clinical guidance for doctors and patients in every } \\
\text { parts of hospital }\end{array}$ & 2.61 & 52.2 & .827 & .001 & 50 & -3.388 \\
\hline Evaluating complains & 3.14 & 62.8 & .872 & .266 & 50 & 1.124 \\
\hline $\begin{array}{l}\text { Comparing new complains with received } \\
\text { complains in last year }\end{array}$ & 2.55 & 51 & .923 & .001 & 50 & -3.488 \\
\hline $\begin{array}{l}\text { Giving relevant parts of hospital feedback for } \\
\text { consistency }\end{array}$ & 2.49 & 49.8 & .925 & .000 & 50 & -3.938 \\
\hline $\begin{array}{l}\text { Presenting solutions for decreasing complains } \\
\text { like educational workshops for developing job } \\
\text { proficiency }\end{array}$ & 2.55 & 51 & .966 & .002 & 50 & -3.335 \\
\hline
\end{tabular}

\subsection{Clinical audit}

Table 8 shows details of our survey on testing items associated with clinical audit. In our survey, Clinical audit effectiveness in improving the quality of treatment maintains the highest value followed by Clinical audit effectiveness and Using appropriate patient satisfaction evaluation.

Table 8

Clinical audit- T-Test results

\begin{tabular}{lllllll}
\hline Items & \multicolumn{5}{c}{$\mathrm{t}$ - value $=3$} \\
\cline { 2 - 7 } & Mean & $\begin{array}{l}\text { Average } \\
\text { percent }\end{array}$ & $\begin{array}{l}\text { Std } \\
\text { deviation }\end{array}$ & p-value & df & t \\
\hline Clinical audit effectiveness & 3.24 & 64.8 & 1.012 & .103 & 50 & 1.661 \\
The amount of using results of audits & 2.86 & 57.2 & 1.000 & .332 & 50 & -.980 \\
$\begin{array}{l}\text { Using appropriate check lists in clinical audit } \\
\text { Using appropriate patient satisfaction evaluation }\end{array}$ & 2.88 & 57.6 & .840 & .322 & 50 & -1.000 \\
$\begin{array}{l}\text { Using appropriate sample in evaluating patient } \\
\text { satisfaction }\end{array}$ & 2.80 & 56 & .749 & .067 & 50 & -1.870 \\
$\begin{array}{l}\text { Clinical audit effectiveness in improving the quality of } \\
\text { treatment }\end{array}$ & 3.45 & 69 & .966 & .002 & 50 & 3.335 \\
$\begin{array}{l}\text { Paying attention to customer (patient ,public ,etc.) } \\
\text { needs like complain results }\end{array}$ & 2.61 & 52.2 & .827 & .001 & 50 & -3.388 \\
$\begin{array}{l}\text { Considering clinical audit as a process of improving } \\
\text { quality not punishment }\end{array}$ & 2.82 & 56.4 & .953 & .192 & 50 & -1.322 \\
\hline
\end{tabular}

\subsection{Staff management}

Similarly, Table 9 specifies our survey on different items associated with clinical audit. In our investigation, Preserving and maintaining worthy staffs maintains the highest amount and the others are less than average. 
Table 9

Staff management- T-Test results

\begin{tabular}{|c|c|c|c|c|c|c|}
\hline \multirow[t]{2}{*}{ Items } & \multicolumn{6}{|c|}{$\mathrm{t}-$ value $=3$} \\
\hline & Mean & $\begin{array}{l}\text { Average } \\
\text { percent }\end{array}$ & $\begin{array}{c}\text { Std } \\
\text { deviation }\end{array}$ & $\mathrm{p}$-value & df & $\mathrm{t}$ \\
\hline Continuing education staffs & 3.35 & 67 & .796 & .003 & 50 & 3.168 \\
\hline Establishing staff satisfaction survey system & 2.43 & 48.6 & .781 & .000 & 50 & -5.199 \\
\hline Personal satisfaction survey system effectiveness & 3.33 & 66.6 & 3.35 & .042 & 50 & 2.082 \\
\hline Establishing justification system for new staffs & 2.37 & 47.4 & .871 & .000 & 50 & -5.145 \\
\hline $\begin{array}{l}\text { Performing staff's encouragement system } \\
\text { effectiveness in improving efficiency of staff duties }\end{array}$ & 2.47 & 49.4 & .966 & .000 & 50 & -3.912 \\
\hline Preserving and maintaining worthy staffs & 3.53 & 70.6 & .966 & .000 & 50 & 3.912 \\
\hline $\begin{array}{l}\text { Informing staffs about their job 's standards and } \\
\text { expectations }\end{array}$ & 2.69 & 53.8 & .883 & .014 & 50 & -2.537 \\
\hline $\begin{array}{l}\text { Mentioning common goals, interest and motivation for } \\
\text { moving toward a direction }\end{array}$ & 2.69 & 53.8 & .905 & .017 & 50 & -2.475 \\
\hline
\end{tabular}

\section{Discussion and conclusion}

Patients are the cores of services and all the works must be carried out in alliance with patient's treatment and improvement to meet their satisfaction (Nguyen Thi et al., 2002). Huge advancements in the field of medicines and treatment together with the recent medical research and training have increased patients' expectations. This has led the healthcare organizations to identify the needs and requirements as well as the risks threatening people and public accurately, and to apply the effective strategies to reach desirable goals associated with the health through implementation of modern and scientific methods and decision-making trends. That's why the CG together with other priorities in healthcare sector such as patients' safety and patients' rights charter are needed to improve the performance of the organizations.

Clinical service governance is a merger of all activities, which integrate patients' care in a unified package. This kind of strategy includes the promotion of information quality, cooperation improvement, collaboration and teamwork improvement, decrease in performance deficiencies and implementation of Evidence Based Medicine.

The primary objective of this research was to survey the implementation of CG at Dr. Shariati's hospital in Tehran based on a seven-pillar CG model. The proposed model of this paper has investigated seven dimensions including Clinical Audit, Clinical Effectiveness, Staff Management, Risk Management, Education and Training, Patient and Public Involvement, and Using Information for this hospital. The results of CG analysis for Dr. Shariati's hospital indicated that the statuses of the CG components were close to the average amount. Although the CG investigation has recently become popular in Iran, the aforesaid results reveal that Dr. Shariati's hospital, as a representative of hospitals in governmental sector, has taken great measures under the umbrella of the CG efforts in Iran. The findings of the study specify accurately the deficiencies in various dimensions of the Clinical Governance. Considering the educational and research approach of the hospital, we expect better performance in the field of training and learning, but the results show that other than training; the findings in clinical audit, using information, and staff management are close to the average amount.

\section{References}

Anne, M., Debbie, K., \& Judy, S. (2006). Clinical Governance improvement initiatives in community nursing. Clinical Governance: An International Journal, 11(3), 198-212.

Authority of the house of commons, health committee (2007). Patient and public involvement in the NHS. Third Report of Session 2006-07.volume I. London: The Stationery Office Limited 
Byers, J. F., \& white, S. v. (2004). Patient Safety:Principles and Practice

Chambers, R., \& Walkley, G. (2000). Making Clinical Governance Work For You

Chandra, S. (2009). Sense making of clinical governance at different levels in NHS hospital trusts . Clinical Governance: An International Journal, 14(2), 98-112.

Clark, C. E., \& Smith, L. F. P. (2002). Clinical governance and education: the views of clinical governance leads in the south west of England. British Journal of Clinical Governance, 7(4), 26-1 .266

Colin-Thome, D. (2013). Development opportunities in the new NHS for personal, population and system care: The coming of age for clinical governance? Clinical Governance: An International Journal, 18(1), 6-17.

Currie, L., Morrell, C. \& Scrivener, R. (2005). Clinical Governance:an RCA resource guid. Royal college of nursing publication.

David, G., Peter, N., Greg, F., Jacqueline, M., \& Deborah, D. (2011). Applying and developing health service theory: an empirical study into clinical governance. Clinical Governance: An International Journal, 16(1), 8-19.

Eleonora, K., Niki, G., \& Kostas, Z. (2011). Assessing hospitals' readiness for clinical governance quality initiatives through organisational climate. Journal of Health Organization and Management, 25(2), 214-240.

Fong, N. (2005). Austrailian Clinical Governance Guidlines.

Gabriel, S., \& Liam, J. D. (1998). Clinical governance and the drive for quality improvement in the new NHS in England. BMJ, 317(7150), 61-65.

Garg, D., Singhal, A., \& Neelam, K. (2012). Clinical audits by trainee doctors: obstacles and solutions. Clinical Governance: An International Journal, 17(1), 45-53.

Frederick, H. K., Russell, M., \& Huw, T. O. D. (2008). Clinical governance views on culture and quality improvement. Clinical Governance: An International Journal, 13(3), 200-207.

Gabriel, S., \& Liam, J. D. (1998). Clinical governance and the drive for quality improvement in the new NHS in England. BMJ, 317(7150), 61-65.

Haxby E, Hunter, D. H., \& Jaggar S. (2010). An Introduction to Clinical Governance and Patient Safety. ${ }^{\text {ed }}$. New York: Oxford University Press.

Hyde, P., Sparrow, P., Boaden, R., \& Harris, C. (2013). High performance HRM: NHS employee perspectives. Journal of Health Organization and Management, 27(3), 296-311.

John, P., Catherine, M., \& Moira, C. (2008). Improving patient care and clinical governance through the utilisation of a clinical information system. Clinical Governance: An International Journal, 13(4), 254-260.

Sandars, J., \& Cook, G. (Eds.). (2007). ABC of patient safety. Wiley. com.

Komuravelli, A., \& Smith, J. (2011). Audits and their impact on clinical practice. Clinical Governance: An International Journal, 16(2), 111-118.

Luu Trong, T. (2012). Clinical governance: a lever for change in Nhan Dan Gia Dinh Hospital in Vietnam. Clinical Governance: An International Journal, 17(3), 223-247.

Marshall, M., Sheaff, R., Rogers, A., Campbell, S., Halliwell, S., Pickard, S., ... \& Roland, M. (2002). A qualitative study of the cultural changes in primary care organisations needed to implement clinical governance. The British Journal of General Practice, 52(481), 641-645.

Moore, J. (2008). Survey of service user involvement in clinical audit. Clinical Governance: An International Journal, 13(3), 192-199.

Pantouvakis, A., \& Mpogiatzidis, P. (2013). Measuring clinical department efficiency â $\epsilon^{\prime \prime}$ the impact of clinical leadership job satisfaction: An application to public hospitals. Benchmarking: An International Journal, 20(3), 305-321.

Nguyen Thi, P. L., Briancon, S., Empereur, F., \& Guillemin, F. (2002). Factors determining inpatient satisfaction with care. Social science \& medicine, 54(4), 493-504.

Reynard, J., Reynolds, J., \& Stevenson, P. (2010). Practical Patient Safety. International Journal of Health Care Quality Assurance, 23(2). 
Savory, C. (2010). Patient and public involvement in translative healthcare research. Clinical Governance: An International Journal, 15(3), 191-199.

Samanta, A., \& Samanta, J. (2005). Evidence-based medicine: A clinical governance tool for rationalising or rationing health care? Clinical Governance: An International Journal, 10(4), 308313.

Som, C. V. (2009). quantity versus quality dilemma of health staff in NHS UK: Does clinical governance provide a solution? Clinical Governance: An International Journal, 14(4), 301-314.

Som, C. V. (2007)/ Exploring the human resource implications of clinical governance. Health Policy, 80(2), 281-296.

Willcocks, S. (2003). Developing the effectiveness of primary care organisations in the UK National Health Service: A case study. Journal of Health Organization and Management, 17(3), 194-209.

Wright, J., \& Hill, P. (2003). clinical governance. Torento: cherchill livingstone. 